Disponível em:

http://editora.unoesc.edu.br/index.php/race

RACE, Joaçaba, v. 16, n. 1, p. 353-380, jan./abr. 2017

\title{
BENEFÍCIOS POTENCIAIS DA AUDITORIA OPERACIONAL PARA A ADMINISTRAÇÃO PÚBLICA: A PERCEPÇÃO DOS AUDITORES DO TCE/PB
}

Potential benefits of the operational auditing for the public administration: the perception of the auditors of the TCE/PB

Gentil Jose Pereira de Melo

E-mail: gentilpermelo@gmail.com

Especialista em Gestão e Auditoria Pública pelo Instituto de Educação Superior da Paraíba; Graduado em Ciências Contábeis pela Universidade Federal da Paraíba; Auditor de Contas Públicas do Tribunal de Contas do Estado da Paraíba.

Simone Bastos Paiva

E-mail: sbpaiva@uol.com.br

Doutora em Administração (Estratégias Empresariais) pela Universidade Federal da Paraíba; Mestre em Administração pela Universidade Federal da Paraíba; Professora no Departamento de Finanças e Contabilidade da Universidade Federal da Paraíba. Endereço para contato: Cidade Universitária, Castelo Branco, 58000-000, João Pessoa, Paraíba, Brasil.

Artigo recebido em 09 de junho de 2016. Aceito em 16 de outubro de 2016. 
Resumo

A auditoria operacional tem sido utilizada pelos tribunais de contas brasileiros para avaliar a administração pública brasileira, visando a correções, melhorias e aperfeiçoamento de setores, programas, políticas e processos governamentais. Nesse contexto, este estudo teve como objetivo analisar a percepção dos auditores do Tribunal de Contas do Estado da Paraíba (TCE/ PB) sobre o grau de importância e a possibilidade de materialização dos benefícios potenciais da auditoria operacional em prol da administração pública. Trata-se de uma pesquisa descritiva e quantiqualitativa, realizada por meio de um levantamento. Para coletar os dados aplicou-se um questionário a 22 auditores do referido Tribunal. Os resultados revelaram que na percepção dos auditores do TCE/PB, dos 15 principais benefícios potenciais apontados pela doutrina, 10 deles têm grandes possibilidades de materialização, permitindo a conclusão de que os benefícios da auditoria operacional se mostram com potencial de promover a melhoria da administração pública.

Palavras-chave: Auditoria operacional. Benefícios da auditoria. Administração pública.

\section{Abstract}

The operational auditing has been used by the courts of Brazilian accounts to evaluate the Brazilian public administration, aiming fixes, improvements and enhancements of sectors, programs, policies and government processes. In this context, this study had as objective analyze the perception of the auditors of the Paraíba Audit Office (TCE/PB) on the degree of importance and the possibility of materialization of the potential benefits of the operational auditing for the public administration. This is a descriptive and quantitative and qualitative research, conducted through a survey. To collect the data applied a questionnaire to 22 auditors of the Court. The results showed that the perception of the auditors of TCE/PB, between the 15 main potential benefits appointed by the doctrine, 10 of them have large possibilities of materialization, allowing the conclusion that the benefits of the operational auditing to show up auditing to promote the improvement of public administration.

Keywords: Operational audit. Audit benefits. Public administration.

\section{INTRODUÇÃO}

Diversas e grandes transformações têm acontecido na administração pública do Brasil ao longo de sua história. Estado e sociedade passaram a experimentar novas relações entre si de modo que a busca por resultados, o foco no cidadão e a democratização da gestão passaram a pautar os rumos da administração pública (LEAL, 2006). Deve-se compreender que as últimas transformações são resultados de reformas que provocaram modificações na maneira de atuar do Estado brasileiro ao 
longo dos tempos. Pode-se destacar, entre os marcos das reformas, a criação do Departamento Administrativo do Serviço Público (DASP), em 1936; do Decreto-Lei n. 200/67; da Constituição Federal de 1988; do Plano Diretor da Reforma do Aparelho do Estado (PDRAE), em 1995; e, mais ultimamente, das exigências de transparência no setor público. Ainda que alguns estudiosos entendam que algumas das reformas não passaram de tentativas de reformas, o fato é que procuraram corrigir rumos e provocaram novos delineamentos para a administração pública (BRASIL, 1995).

Pode-se observar que, ao longo do tempo, ocorreu a transição de um modelo burocrático para um gerencial, de um modelo dominado por meios e processos para um modelo com ênfase nos fins e resultados (SOUZA, 2007). A sociedade brasileira, afetada por essas mudanças, passou a exigir uma melhor utilização dos recursos públicos, no sentido de que eles se revertam no atendimento às necessidades dos cidadãos (RIBEIRO FILHO et al., 2010).

Os tribunais de contas, na posição de órgãos de controle externo da administração pública, por exemplo, têm procurado ampliar suas ações, passando a verificar e a acompanhar melhor a prestação de serviços públicos e o desempenho dos órgãos públicos. No cumprimento dessa incumbência, os tribunais de contas têm utilizado a auditoria operacional, que, de acordo com Haller (1985 apud ARAÚJO, 2008), é uma importante ferramenta que permite avaliar e comunicar o uso eficiente dos recursos e o alcance dos resultados desejados.

O instrumento ganha força mediante os benefícios que pode oportunizar, assim, o processo de solidificação da auditoria operacional acontecerá por meio da materialização de seus objetivos e dos benefícios que sua aplicação possa promover em prol da administração pública. Estudiosos (ALMEIDA, 2012; ARAÚJO, 2008; SILVA, 2006) e organismos brasileiros e internacionais (Tribunal de Contas da União (TCU), International Organisation of Supreme Audit Institutions (Intosai), Government Accountability Office (GAO)) elencam um rol desses benefícios.

Nesse contexto, tribunais de contas, inclusive o Tribunal de Contas do Estado da Paraíba (TCE/PB), têm atuado em processos de auditorias operacionais, de modo a contribuírem com mais efetividade para a melhoria da gestão pública. Assim, o objetivo com o presente estudo foi analisar a percepção dos auditores do TCE/PB sobre o grau de importância e a possibilidade de materialização dos benefícios potenciais da auditoria operacional em prol da administração pública. Sendo a auditoria operacional no setor público prática recente e com carência de tratamento, a análise pode resultar em melhor conhecimento do tema e em contribuições para o aperfeiçoamento da auditoria operacional. 
A realização de 10 trabalhos de auditoria operacional desde a implantação da atividade no rol de suas atribuições em 2008, a expertise do órgão ampliada a partir de cooperações técnicas com o Tribunal de Contas da União (TCU), com a Associação dos Tribunais de Contas do Brasil (Atricon), com o Instituto Rui Barbosa (IRB) e com outros tribunais de contas brasileiros, e as prioridades estratégicas de intensificar ações de orientações aos jurisdicionados por meio da realização de auditorias operacionais e de qualificar o órgão para avaliar programas e projetos são aspectos que servem de justificativa para a escolha do TCE/PB para o estudo.

\section{REVISÃO DE LITERATURA}

A administração pública brasileira, desde a segunda metade do século XX, tem buscado, de maneira incessante, instrumentos capazes de torná-la mais eficiente e eficaz. A sociedade cobra retornos e exige, em grau cada vez mais elevado, providências adequadas para o atendimento das necessidades coletivas e ações incisivas que coíbam a corrupção, a impunidade e os desmandos. É necessário que a administração pública tenha a capacidade de colocar em funcionamento as mudanças que repercutam em serviços de melhor qualidade prestados ao cidadão, em maior produtividade dos modelos utilizados e no direcionamento do foco das ações (DIAS NETO, 2005).

Na visão de Olivieri et al. (2012), o processo de monitoramento das políticas públicas, com o objetivo de promover o desempenho e a eficiência dessas políticas, tem sido objeto de preocupação, em virtude de que os governos assumem crescentes responsabilidades no provimento de serviços públicos aos cidadãos, e isso, quase sempre, em um cenário de limitação orçamentária.

A atuação estatal, com o objetivo de concretizar as políticas públicas, exige um sistema de avaliação em condições de garantir a verdadeira eficiência dos programas governamentais. Tem-se, assim, a utilização da auditoria operacional como uma opção importante para avaliar o desempenho do setor governamental.

\subsection{EVOLUÇÃO HISTÓRICA DA AUDITORIA OPERACIONAL NOS TRIBUNAIS DE CONTAS}

A auditoria operacional, no setor governamental, teve o seu desenvolvimento impulsionado pelos trabalhos realizados pelo Escritório de Accountability Governamental dos Estados Unidos (GAO) e por outras organizações de auditoria, em âmbito estadual do governo norte-americano (ARAÚJO, 2008). 
A aprovação pela Organização Internacional das Entidades Fiscalizadoras Superiores/International Organisation of Supreme Audit Institutions (Intosai), em 1971, do conceito de "auditoria integral” ou “integrada”, envolvendo as responsabilidades contábil, administrativa e programática, inicia o processo de sistematização da auditoria operacional como ramo da auditoria na área governamental (ARAÚJO, 2008).

Por meio das discussões travadas no XII Congresso da Intosai, realizado em Sydney, Austrália, em 1986, reconheceu-se a necessidade de promover melhorias na divulgação das demonstrações financeiras e dos resultados das atividades e de aperfeiçoamentos na gestão do setor público por meio do desenvolvimento da auditoria operacional (ARAÚJO, 2008).

No Brasil, a incorporação da concepção de auditoria operacional no Texto da Constituição Federal de 1988 representou tomada de consciência dos políticos e administradores públicos (SILVA, 1993 apud LEAL, 2006).

Em 1998, o Tribunal de Contas da União publicou o seu Manual de auditoria de desempenho, conceituando esta como a que consiste na avaliação sistemática dos programas, projetos e atividades governamentais, assim como dos órgãos e entidades jurisdicionados ao Tribunal (ARAÚJO, 2008).

A Lei Federal Complementar n. 101, de 2000, conhecida como a Lei de Responsabilidade Fiscal, trouxe comando de determinação ao Poder Legislativo, aos Tribunais de Contas, ao controle interno de cada Poder e ao Ministério Público de fiscalização com ênfase em fatos que comprometam os custos ou os resultados dos programas. Essa ênfase, na visão de Feil (2007), representou uma reiteração ao preconizado pelo comando constitucional de uma fiscalização orientada para o desempenho.

No ano 2005 ocorreu a instituição do Programa de Modernização do Sistema de Controle Externo dos Estados, Distrito Federal e Municípios brasileiros, denominado Promoex, com o objetivo principal de fortalecer o referido sistema por meio da integração nacional e da modernização dos tribunais de contas, considerando como prioritária a implantação de auditorias operacionais no País (NAVES, 2012).

Vê-se nessa evolução da auditoria no setor governamental brasileiro que os tribunais de contas se tornaram órgãos relevantes no acompanhamento e no controle das atividades (BACK, 1991). Paula (2012), referindo-se ao assunto, assinala que a Lei de Responsabilidade Fiscal deu novo impulso aos tribunais de contas, ao reforçar a importância deles para a garantia do bom uso do dinheiro público, o que contribui para que os recursos despendidos pelo Governo sejam aplicados no atendimento às necessidades requeridas pela sociedade. 
Ao discorrerem que a utilização de mecanismos de controle de resultados representou uma das maiores novidades em termos de accountability democrática, Teixeira et al. (2010) ressaltaram que a verdadeira novidade não era tanto os atores que fiscalizam, mas o objeto a ser fiscalizado. Esclareça-se que o significado do termo accountability, sem tradução exata para a Língua Portuguesa, remete à obrigação de prestação de contas e à responsabilização de administradores (ARAÚJO, 2008).

Olivieri et al. (2012) apontam que os órgãos de controle, em processo de expansão, têm se conduzido com a orientação de que o controle persegue objetivos os quais vão além do combate à corrupção, focando também na melhoria do desempenho da gestão pública.

Infere-se, assim, que os órgãos de controle passaram a ter uma real capacidade e uma grande responsabilidade de interferir nas políticas públicas de maneira muito mais efetiva. A cultura punitiva, até então predominante nos tribunais de contas, passou a abrir espaço para a necessidade de contribuir de forma mais relevante para o aprimoramento da gestão pública e, por conseguinte, os tribunais de contas passaram a estar mais próximos da sociedade.

\subsection{DENOMINAÇÕES E CONCEITOS DA AUDITORIA OPERACIONAL}

Estudos elencam várias denominações para a auditoria de natureza operacional. No Brasil, a denominação predominante é auditoria operacional, expressão incorporada pelo TCU, por exemplo, desde 2010 (BRASIL, 2010).

Variados também são os conceitos normalmente associados à auditoria operacional pelas organizações internacionais e nacionais e pela doutrina. Araújo (2008, p. 34) apresenta o conceito de auditoria operacional, proposto pela Intosai, como “[...] a auditoria de economicidade, eficiência e eficácia com que a unidade auditada utiliza seus recursos no desempenho de suas atribuições.” O GAO (1995 apud ARAÚJO, 2008) classifica a auditoria operacional como um exame objetivo e sistemático de evidências que têm a finalidade de fazer uma avaliação independente do desempenho de uma organização, programa, atividade ou função de governo e, com isso, informações são fornecidas para serem utilizadas no processo de melhoria da accountability pública e no de tomada de decisões pelos envolvidos na tarefa de supervisionar ou iniciar ações corretivas.

Em síntese, tem-se a auditoria operacional como uma ação independente que visa à melhoria da accountability pública e ao aperfeiçoamento da gestão pública. De 
maneira simples, a auditoria operacional é a auditoria que busca verificar se se agiu corretamente, da forma melhor e mais econômica (ARAÚJO, 2008).

O TCU, por meio do atual Manual de auditoria operacional (BRASIL, 2010), expõe que auditoria operacional é a verificação independente e objetiva da economicidade, eficiência, eficácia e efetividade de organizações, programas e atividades governamentais, com o objetivo de promover o aperfeiçoamento da gestão pública.

Em uma análise dos conceitos atribuídos à auditoria operacional por organismos internacionais e nacionais e pela doutrina, verifica-se a referência a dimensões como economia (ou economicidade), eficiência, eficácia e efetividade. A essência da auditoria operacional tem relação com a compreensão das definições das dimensões que são propostas. Nem sempre as dimensões são definidas da mesma forma pelos organismos e pela doutrina.

O Quadro 1 apresenta as definições adotadas pelo TCU para as principais dimensões da auditoria operacional.

Quadro 1 - Definições adotadas pelo TCU para dimensões da auditoria operacional

\begin{tabular}{|l|l|}
\hline \multicolumn{1}{|c|}{ Dimensão } & \multicolumn{1}{c|}{ Definição } \\
\hline Economicidade & $\begin{array}{l}\text { "É a minimização dos custos dos recursos utilizados na consecução de uma ativi- } \\
\text { dade, sem comprometimento dos padrões de qualidade." (ISSAI 3000/1.5, 2004 } \\
\text { apud BRASIL, 2010). }\end{array}$ \\
\hline Eficiência & $\begin{array}{l}\text { "[...] a relação entre os produtos (bens e serviços) gerados por uma atividade e os } \\
\text { custos dos insumos empregados para produzi-los, em um determinado período de } \\
\text { tempo, mantidos os padrões de qualidade." (BRASIL, 2010). }\end{array}$ \\
\hline Eficácia & $\begin{array}{l}\text { "É o grau de alcance das metas programadas (bens e serviços) em um determinado } \\
\text { período de tempo, independentemente dos custos implicados.” (COHEN; FRAN- } \\
\text { CO, 1993 apud BRASIL, 2010). }\end{array}$ \\
\hline Efetividade & $\begin{array}{l}\text { "Trata-se de verificar a ocorrência de mudanças na população-alvo que se poderia } \\
\text { razoavelmente atribuir às ações do programa avaliado" (COHEN; FRANCO, 1993 } \\
\text { apud BRASIL, 2010). }\end{array}$ \\
\hline
\end{tabular}

Os limites entre as dimensões não são estabelecidos de maneira muito fácil, e os aspectos diretamente ligados a essas dimensões podem ser analisados de modo particular ou de forma conjunta (ARAÚJO, 2008).

Por meio da verificação do cumprimento do preconizado pelas dimensões, a auditoria operacional é a modalidade de auditoria governamental que tem a finalidade de constatar se o que foi auditado (órgão, programa, projeto, atividade) alcançou os 
resultados pretendidos, considerando-se, ainda, se foi no tempo certo e a um custo minimamente possível.

\subsection{ETAPAS DE EXECUÇÃO DA AUDITORIA OPERACIONAL}

A auditoria operacional se desenvolve de acordo com um ciclo complexo de fases complementares e sequenciais. No TCU, por exemplo, e de acordo com o seu Manual (BRASIL, 2010), o desenvolvimento obedece ao seguinte ciclo: seleção, planejamento, execução, relatório, comentário do gestor, apreciação, divulgação e monitoramento.

O início do ciclo ocorre com a seleção do objeto da auditoria, ou seja, do tema a ser tratado. Nessa fase, um dos critérios essenciais a ser adotado é o da relevância, uma vez que a auditoria operacional, nas palavras de Almeida (2014), deve selecionar as organizações e os programas que tenham maior impacto para a sociedade e/ou para a gestão pública.

Na fase de planejamento, procura-se identificar os pontos mais importantes que devem ser abordados na avaliação, com o objetivo de elaborar a metodologia de trabalho e o instrumental mais conveniente para obter os dados e as informações necessárias para cada questionamento ou área de interesse selecionada no processo (FEIL, 2007). Além disso, segundo o Manual do TCU (BRASIL, 2010), nesse estágio são estimados os recursos, os custos e o prazo necessários para a realização da auditoria. O documento resultante do planejamento, denominado plano de auditoria, não é estático e deve ser atualizado quando as circunstâncias determinarem (ARAÚJO, 2008).

Na execução ocorre a aplicação dos procedimentos de auditoria, com o objetivo de obter as provas ou evidências que constarão no relatório de auditoria, e é também nessa fase que o auditor realiza fundamentalmente seus exames (ARAÚJO, 2008). De maneira geral, a coleta e a análise de dados não são atividades estanques, pois dependendo do procedimento de metodologia adotado no plano de auditoria, a organização dos trabalhos de campo e a estratégia de análise de dados podem sofrer variações significativas (BRASIL, 2010).

O principal produto da auditoria é o relatório, por meio do qual são comunicados o objetivo, as questões de auditoria, a metodologia usada, os achados, as conclusões e a proposta de encaminhamento (BRASIL, 2009 apud BRASIL, 2010). No relatório constam, principalmente, as recomendações e as determinações direcionadas para a administração pública. As constatações devem ser transmitidas de forma completa, clara, concisa, correta e imparcial, para que todos os atores interessados na 
matéria objeto de auditoria operacional possam compreender o objetivo da auditoria e os resultados (ARAÚJO, 2008).

Após a elaboração, o relatório preliminar é submetido aos gestores dos programas auditados para que possam fazer comentários sobre os problemas identificados e as propostas de encaminhamento, que, após a análise dos auditores, são incorporados à versão final do relatório (MORAES, 2007). Uma das propostas é de que o auditado elabore e encaminhe ao tribunal de contas um plano de ação, documento que deve conter cronograma de materialização das medidas que o gestor adotará com a finalidade de atender às deliberações propostas e de corrigir os problemas levantados (BRASIL, 2010).

A apreciação do relatório final é feita pelos membros dos tribunais de contas, que, no caso do TCU, ocorre pelos ministros, e, no caso dos tribunais de contas estaduais e municipais, pelos conselheiros. Depois de apreciado, o relatório passa pelo estágio da ampla divulgação, para que os resultados das ações estatais avaliadas sejam conhecidos pela sociedade, possibilitando que esta acompanhe e se mobilize na materialização das recomendações e determinações pelos gestores públicos (MORAES, 2007).

Por fim, na fase de monitoramento ou acompanhamento, foi verificado o cumprimento das deliberações dos tribunais de contas e dos resultados delas advindos, com o intuito de se constatar quais as providências adotadas e aferir seus efeitos (BRASIL, 2010). Além de acompanhar a evolução do desempenho dos órgãos auditados, o monitoramento possibilita a retroalimentação do processo, pois os gestores tomam conhecimento de quais ações ainda precisam adotar e se medidas já adotadas estão contribuindo para que os resultados desejados sejam alcançados (FEIL, 2007).

\subsection{BENEFÍCIOS POTENCIAIS PARA A MELHORIA DA ADMINISTRAÇÃO PÚBLICA}

A doutrina e o proposto e/ou experimentado por organizações internacionais e nacionais relacionam os diversos benefícios que, potencialmente, são oportunizados mediante a auditoria operacional no setor público. Ressalte-se a referência aos benefícios como potenciais, uma vez que a materialização deles depende de adoção de providências por parte do gestor público em relação aos apontamentos realizados pela auditoria operacional. 


\subsubsection{Avaliação de resultados da administração pública com foco no cidadão}

A realização dos trabalhos preocupa-se com a ideia de que o cidadão seja visto como destinatário das políticas públicas. A atenção da auditoria operacional busca verificar se os resultados das políticas públicas conseguem manter a satisfação do cidadão (ALMEIDA, 2012). Importante registrar que a preocupação com a lei não deixa de existir, mas os resultados somente podem ser considerados adequados se as necessidades do cidadão forem atendidas (ALMEIDA, 2012).

\subsubsection{Fomento ao controle social}

Por meio dos relatórios da auditoria operacional a sociedade tem conhecimento sobre os resultados das ações estatais avaliadas, o que pode contribuir para mobilizar a comunidade no acompanhamento e na apreciação dos objetivos, da materialização e dos resultados das políticas públicas (MORAES, 2007). Considerando que por intermédio da auditoria operacional se busca a verificação da eficiência, da economicidade, da eficácia e da efetividade na execução dos programas de governo, esse é o tipo de auditoria que interessa mais de perto à população (SILVA, 2006).

\subsubsection{Melhoria da supervisão exercida pelo Poder Legislativo}

De maneira geral, ao Poder Legislativo compete a supervisão do uso dos recursos pelas organizações públicas de todas as esferas do Poder Público. Nesse contexto, a auditoria operacional se firma como ferramenta fundamental para a fiscalização e o fortalecimento dessa fiscalização legislativa. Estudos realizados por Almeida (2012) evidenciam que a auditoria operacional permite ao Poder Legislativo constatar se a despesa pública produz concretamente os bens e serviços esperados, identificar falhas e propor medidas de aperfeiçoamento.

\subsubsection{Divulgação de informação mais qualificada}

O fato de a auditoria operacional realizar um exame que vai além da observância da legalidade e focar no desempenho faz com que a informação apurada esteja dotada de mais qualificação, de modo que a informação divulgada seja bem 
construída. Para isso, é fundamental a identificação da natureza e a fonte das evidências de auditoria. O auditor John Sweeney, do Tribunal de Contas Europeu, destacou que o auditor deve obter evidências em quantidade suficiente e que sejam apropriadas para responder às questões de auditoria, permitir conclusões e propor recomendações. Ainda na visão de Sweeney, os auditores devem ser receptivos a pontos de vista alternativos e buscar informações em diferentes fontes e atores (AUDITOR..., 2010).

\subsubsection{Melhoria das relações entre auditoria e auditado}

Uma relação cooperativa entre auditor e auditado muito contribui para o sucesso de uma auditoria operacional. Como da auditoria operacional resultam informações importantes para o desempenho governamental, o gestor bem-intencionado tem grande interesse na sua realização. Sendo do interesse de ambos, do órgão auditor no cumprimento de sua missão e do órgão auditado na busca de feedback de seu desempenho, a aproximação torna-se interessante. Integra os ensinamentos de Sweeney (AUDITOR..., 2010), com recomendação de manutenção de boas relações profissionais entre auditores e auditados por meio do estabelecimento de uma troca de informações livre e franca e da realização de discussões baseadas em respeito mútuo, atentando, porém, para que não sejam ultrapassados os limites do bom relacionamento profissional e cooperativo e não seja prejudicada a necessária independência.

\subsubsection{Melhoria do debate sobre as políticas governamentais}

Políticas governamentais constituem tema presente em programas de partidos políticos, em programas de governos, no conteúdo da imprensa e, de maneira mais acentuada, nas comissões temáticas do Poder Legislativo. Dados e informações oriundos da auditoria operacional, revestidos do requinte de análise, podem promover melhoria nos debates acerca das políticas governamentais. Esses debates, algumas vezes, são vazios, em virtude da insuficiência de elementos necessários. A melhoria pode ocorrer se os aspectos trabalhados pela auditoria operacional forem contemporâneos aos fatos. Na concepção de Speck (2012; 2013b), o grau de interesse dos parlamentares depende da proximidade entre os resultados dos trabalhos de auditoria e os fatos atuais. Esse interesse se estende à imprensa, à administração pública, ao controle social e, em suma, à sociedade como um todo. 


\subsubsection{Redução de custos}

Na síntese de Araújo (2008) está a redução de custos entre os benefícios potenciais da auditoria operacional. Esse autor apresenta que nos benefícios potenciais relacionados pelo American Institute of Certified Public Accountants (AICPAs) está o de que a auditoria operacional pode identificar áreas que contribuem para uma possível diminuição ou limitação de custos, e nos relacionados pelo GAO está o de verificar se a administração considerou alternativas para a execução do programa que poderiam conduzir aos resultados desejados a menor custo. Estudos de Oliveira e Siqueira (2012) concluíram que por meio da auditoria operacional a sociedade passa a participar da administração pública e as atitudes de identificar falhas e desvios, de propor melhorias e mudanças e de fiscalizar e monitorar concorrem para a otimização de gastos e de redução de custos.

\subsubsection{Aumento de receitas}

Consta na síntese de Araújo (2008) o aumento de receitas como um dos benefícios potenciais que pode ser proporcionado pela auditoria operacional. Na relação de benefícios potenciais do AICPA, apresentada por Araújo (2008), encontra-se o de que, com a aplicação da auditoria operacional, pode ser conseguida a identificação de áreas que contribuam para um possível aumento de lucros ou receitas. Vê-se que, mesmo com o predomínio da doutrina sobre auditoria operacional fazendo referências a aspectos da despesa pública, existe também a preocupação com a receita pública. Essa preocupação da auditoria operacional tem consonância com o preconizado na Lei de Responsabilidade Fiscal (LRF) em relação à previsão, à arrecadação e à renúncia da receita pública. É requisito para uma gestão fiscal responsável, de acordo com a LRF, que o ente da Federação institua, faça previsão e efetivamente arrecade todos os tributos de sua competência (BRASIL, 2000).

\subsubsection{Solidificação da legitimidade do sistema de controle externo exercido pelos tribunais de contas}

Destaque-se a importância do controle em razão da necessidade de se assegurar a melhor prestação pelo setor público, mais ainda, da necessidade de se aprimorarem os serviços públicos. E, nesse sentido, a sociedade quer mais. É da perspectiva 
de Silva (2006) que, no controle da administração pública, os tribunais de contas não se reduzam ao exame da conformidade e da regularidade e dos gastos públicos, avaliando também os aspectos da economia, eficiência, eficácia e efetividade, utilizando para tal o instrumento da auditoria operacional. Os tribunais de contas que tenham compromisso com o objetivo de tornar a administração pública mais transparente e de subsidiar o controle social com informações gozarão de credibilidade com a sociedade (SPECK, 2012; 2013a). O desenvolvimento da auditoria operacional como uma nova atividade exigiu que tribunais de contas buscassem mais aprendizagem nas universidades e entidades similares, a fim de melhor enfrentar a nova função (MORAES, 2007). Tornaram-se muito comum, também, os acordos técnicos de cooperação entre os tribunais de contas e outros órgãos da administração pública, como forma de diminuir as dificuldades de atuação dos tribunais de contas e dos outros órgãos partícipes do acordo. Tem-se que, com mais e melhores informações, originadas das auditorias operacionais e disseminadas pelos tribunais de contas, são muitos os ganhos para a administração pública em termos da boa e regular aplicação dos recursos.

\subsubsection{Estímulo às boas práticas da administração pública}

Os casos constatados devem ser incluídos nos resultados da auditoria, para que toda a administração pública tome conhecimento e para que essas boas práticas passem a integrar o conjunto de atitudes de outros administradores. A prática da boa governança firma-se como necessidade diante dos desafios da globalização em termos de efetividade, eficiência e responsabilidade que enfrenta a administração pública (DINIZ; MUNIZ JÚNIOR, 2013).

\subsubsection{Escolha de objetos de avaliação que sirvam ao interesse público e à sociedade}

Muitos dos objetos de auditoria escolhidos incluem áreas sensíveis de interesse dos movimentos sociais que em geral não encontram expressão nos meios de comunicação e que, também por esse motivo, podem não ser áreas identificadas pela

opinião pública (SILVA, 2012; 2013). Cabível compreender que o tamanho do campo de atuação é enorme e, como frequentemente o tempo e os recursos disponíveis não permitem o exame de todas as áreas consideradas críticas, devem ser determinadas prioridades que permitam um exame profundo das áreas selecionadas 
(BACK, 1991). Para superar as tantas dificuldades e considerando as exigências da sociedade, o caminho é ter essa própria sociedade como referência. Na ótica de Speck (2012; 2013a), a sociedade civil pode servir de referência tripla para os tribunais de contas, como de fonte de legitimidade para a existência dos tribunais de contas, de colaboradora quando identifica falhas no gasto público e, por fim, de alavanca quando garante que os resultados dos tribunais de contas revertam em benefícios públicos.

\subsubsection{Melhoria do desempenho da administração pública}

Entre os benefícios potenciais da auditoria operacional elencados por Araújo (2008) está o de poder proporcionar a melhoria da administração pública. Dos benefícios potenciais listados pelo GAO, Araújo (2008) anota o de identificar os fatores inibidores de um desempenho satisfatório. A Intosai (2005 apud DINIZ; MUNIZ JÚNIOR, 2013) indica como benefício potencial o de determinar se a administração desempenhou suas atividades com economia, de acordo com os princípios, práticas e políticas administrativas corretas. Estudos de Britto (2014) apontam que as dimensões consideradas pelo controle externo na atividade de auditoria operacional contribuem para a melhoria do desempenho da administração pública.

\subsubsection{Diminuição de desperdícios e de práticas ineficientes, antieconômicas, ineficazes e abusivas}

A diminuição de desperdícios e de práticas ineficientes, antieconômicas, ineficazes e abusivas é registrada por Araújo (2008) como um dos benefícios potenciais que a administração pública pode ter a partir do avaliado pela auditoria operacional. No rol dos benefícios potenciais apontados pelo AICPA, conforme Araújo (2008), estão os de identificação de áreas problemáticas e de suas causas e a identificação de cursos de ações alternativos. A identificação de alternativas também é um dos objetivos indicados pelo GAO, nos termos de que a auditoria operacional pode verificar se a administração considerou alternativas para a execução de um programa que, com maior eficácia, poderiam conduzir aos resultados desejados (ARAÚJO, 2008). Dos benefícios potenciais apontados pela Intosai (2005 apud DINIZ; MUNIZ JÚNIOR, 2013) que têm relação com a diminuição de práticas ineficientes está o de que a auditoria operacional pode determinar se os recursos humanos, financeiros e de qualquer outra natureza são utilizados com eficiência. 


\subsubsection{Avaliação dos objetivos de programas e de organizações}

Quanto a programas, nos benefícios potenciais da auditoria operacional relacionados pelo GAO estão os de avaliar se os objetivos desses programas são apropriados, convenientes ou relevantes e ainda os benefícios de verificar se eles complementam outros programas relacionados, sobrepõem-se ou conflitam-se com eles (ARAÚJO, 2008). Quanto a organizações, o AICPA aponta como benefícios potenciais da auditoria operacional os de avaliar o cumprimento dos objetivos dessas organizações, os de identificar critérios para avaliar o grau de consecução desses objetivos e os de identificar os objetivos ainda não definidos (ARAÚJO, 2008). Já a Intosai (2005 apud DINIZ; MUNIZ JÚNIOR, 2013) dispõe que, ao avaliar os resultados alcançados em relação aos resultados pretendidos, um dos benefícios potenciais da auditoria operacional é o de determinar a eficácia do desempenho das entidades auditadas em relação ao alcance dos seus objetivos.

\subsubsection{Contribuição para a accountability}

Na síntese dos benefícios potenciais formulada por Araújo (2008) está o de que a auditoria operacional contribui para a accountability da administração pública. No novo modelo de administração pública, em que os gestores possuem mais autonomia gerencial, como forma de serem mais eficientes, o cidadão precisa de mais informações para ter condições de avaliar, criticar, reivindicar e até elogiar a atuação desses gestores (BRITTO, 2014). Sendo um exame objetivo e sistemático do desempenho de uma organização, programa, atividade ou função governamental, a auditoria operacional oportuniza mais elementos, com a melhoria da accountability pública e facilitando a tomada de decisões por supervisores da administração, por cidadãos, pelo controle social e por investidores (BRITTO, 2014).

Tem-se, assim, uma síntese dos principais benefícios da auditoria operacional como instrumento potencial de melhoria da administração pública, que foram relacionados por estudiosos da administração pública e de auditoria no setor público, tratados neste estudo. Em termos empíricos, a temática será discutida na perspectiva de auditores públicos, de modo a se proceder a análise acerca da concretização dos benefícios da auditoria operacional em prol da administração pública, tendo como campo de pesquisa o TCE/PB. 


\section{PROCEDIMENTOS METODOLÓGICOS}

Esta pesquisa, com base nos objetivos, é descritiva; quanto aos procedimentos é bibliográfica e de levantamento; e quanto à abordagem do problema é quantiqualitativa.

O objetivo de identificar qual a percepção de auditores do TCE/PB sobre os benefícios potenciais da auditoria operacional caracteriza o estudo, de maneira predominante, como uma pesquisa descritiva, pois esta, de acordo com Gil (2002), procura descrever as características de determinada população ou fenômeno ou o estabelecimento de relações entre variáveis.

Com a finalidade de contextualizar, fez-se necessária a utilização de pesquisa bibliográfica, que, na acepção de Gil (2002), é desenvolvida com base em material já elaborado, formado principalmente de livros e artigos científicos. Por meio da pesquisa bibliográfica foi possível elencar os principais benefícios potenciais da auditoria operacional. Utiliza-se, ainda, a técnica de levantamento de dados, que, na dicção de Gil (2002), caracteriza-se pela interrogação de forma direta das pessoas cujo comportamento se procura conhecer. No presente estudo buscou-se conhecer a percepção de profissionais que lidam com a auditoria operacional sobre os benefícios potenciais desta.

Na abordagem do problema, o estudo é quantiqualitativo. Quantitativo em virtude da utilização de procedimentos estatísticos descritivos na organização dos dados coletados via questionário e da apresentação deles em gráfico e tabelas para uma melhor visualização e compreensão. Qualitativo em decorrência da análise aplicada aos dados e, ainda, da formulação de impressões atinentes a ranqueamentos e possibilidades de materialização de benefícios potenciais. Segundo Prates (2005 apud MELATI, 2013), a pesquisa quantiqualitativa trabalha com dados de fácil quantificação e qualificação e complementa-os com dados subjetivos ou descritivos.

Após elencados os benefícios potenciais, elaborou-se um questionário com questões do tipo fechadas, para fins de obter a percepção dos auditores do TCE/PB. Construir um questionário compreende o fato de traduzir os objetivos da pesquisa em questões específicas (GIL, 2002).

O questionário continha questões sobre o nível de importância dos benefícios potenciais e sobre a chance de os benefícios potenciais da auditoria operacional se materializarem.

As respostas das questões sobre o nível de importância dos benefícios potenciais variaram de 1 a 15, atribuindo-se menor valor para o item mais importante. As respostas foram tratadas por meio de escala de ordenamento ou ranqueamento força- 
do, que, de acordo com Cooper e Shindler (2003), classifica atributos/características em ordem de preferência.

As questões sobre as possibilidades de os benefícios potenciais serem materializados tiveram seus dados coletados com base em uma escala tipo Likert. Segundo Martins e Lintz (2000), esse método consiste em um conjunto de itens apresentados em forma de afirmações e pede-se que os respondentes escolham um dos cinco ou sete pontos de uma escala. Para todas as afirmações solicitou-se que os respondentes assinalassem sua percepção conforme as opções muito alta, alta, moderada, pequena e remota.

O tratamento dos dados contou com o auxílio de planilha eletrônica, obedecendo-se em qualquer situação aos critérios das escalas (ranqueamento forçado e tipo Likert) e, por último, os resultados passaram por análise.

A internalização da prática da auditoria operacional no TCE/PB ocorreu em 2008, tendo sido desenvolvidos 10 trabalhos até o momento, podendo-se destacar as análises da Estratégia Saúde da Família no Estado da Paraíba, em 2010; dos Sistemas de Abastecimento de Água na Paraíba, em 2011; da Mobilidade Urbana, em 2013; da Educação, com foco na rede estadual de Ensino Médio, em 2014; e do Desenvolvimento Econômico do Estado, com foco no Sistema de Incentivos à Indústria, em 2014.

Dos 156 auditores existentes nos quadros do TCE/PB (TRIBUNAL DE CONTAS DO ESTADO DA PARAÍBA, 2015), 23 atuaram em processos de auditoria operacional, aos quais foram entregues os questionários, obtendo-se o retorno de 22. A opção de verificar a percepção apenas dos auditores que já participaram dos procedimentos de auditoria operacional deve-se ao fato de que esses profissionais, em decorrência das atividades desenvolvidas, acumularam conhecimentos e experiências práticas em maior grau, concorrendo, assim, para tornar este estudo mais preciso.

\section{APRESENTAÇÃO DOS RESULTADOS}

Quanto ao perfil dos pesquisados a respeito do tempo de atuação como auditor no TCE/PB, predomina a faixa entre 6 e 10 anos, com 12 respondentes, entre 16 e 20 anos, com 7, e acima de 20 anos, com 3 respondentes; a graduação predominante entre eles é na área de Engenharia (11), seguida por Ciências Contábeis (8), Direito (7) e Administração (4). Registre-se que alguns dos participantes possuem mais de uma graduação. No que se refere à pós-graduação, 18 deles possuem especialização, sendo esta o tipo de pós-graduação da maioria dos auditores do TCE/PB que participaram da pesquisa. 


\subsection{PERCEPÇÃO DOS AUDITORES DO TCE/PB QUANTO AOS BENEFÍCIOS POTENCIAIS DA AUDITORIA OPERACIONAL}

No Gráfico 1 demonstra-se a ordem de importância dos principais benefícios potenciais da auditoria operacional em favor da administração pública, na ótica dos auditores do TCE/PB. Registre-se que, pela escala de ordenamento ou ranqueamento forçado, os itens com menor pontuação são os preferidos.

Gráfico 1 - Grau de importância dos principais benefícios potenciais da auditoria operacional

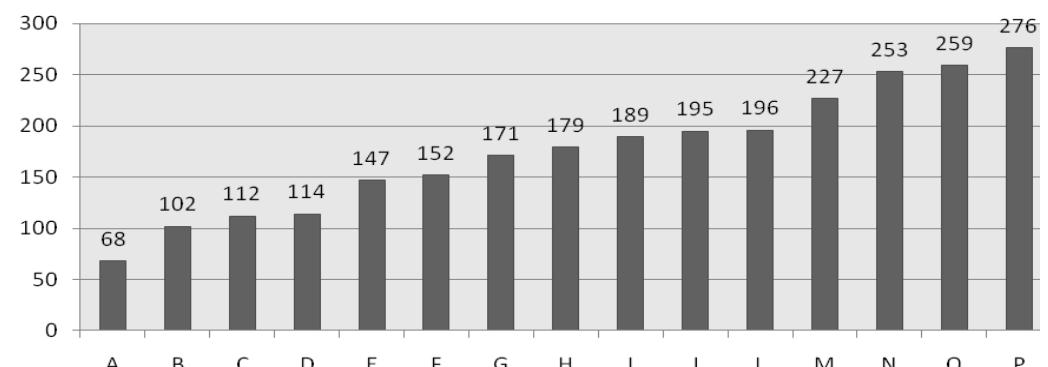

A - Melhoria do desempenho da administração pública

B - Diminuição de desperdícios e de práticas ineficientes, antieconômicas, ineficazes e abusivas

C - Estímulo às boas práticas da Administração Pública

D - Avaliação de resultados da administração pública com foco no cidadão

E - Avaliação dos objetivos de programas e de organizações

$\mathrm{F}$ - Melhoria do debate sobre as políticas governamentais

G - Solidificação da legitimidade do sistema de controle externo exercido pelos tribunais de contas

H - Escolha de objetos de avaliação que sirvam ao interesse público e à sociedade

I - Contribuição para accountability

$\mathrm{J}$ - Fomento ao controle social

L - Redução de custos

M - Divulgação de informação mais qualificada

N - Melhoria das relações entre auditoria e auditado

O - Aumento de receitas

P - Melhoria da supervisão exercida pelo Poder Leqislativo

Fonte: os autores.

De acordo com os respondentes, o benefício potencial mais importante da auditoria operacional é o de possibilitar a melhoria do desempenho da administração pública, pois obteve 68 pontos. Por tratar de desempenho, pode-se creditar a isso o grau de importância atribuído a esse aspecto pelos auditores do TCE/PB. Registre-se que a melhoria do desempenho consegue, de certa forma, reunir em si todos os demais potenciais benefícios da auditoria operacional. Esse aspecto pode explicar o patamar alcançado pelo benefício na avaliação dos auditores do TCE/PB. 
Em seguida, foram percebidos também como importantes os benefícios potenciais referentes à diminuição de desperdícios, ao estímulo às boas práticas, à avaliação dos resultados com foco no cidadão, aos objetivos de programas e de organizações, à melhoria dos debates sobre as políticas governamentais, à legitimidade dos tribunais de contas e à escolha de objetos de interesse da sociedade, com pontuação entre 102 e 179.

Em um cenário com existência de práticas por gestores públicos que colidem com os anseios da população, o encontro de boas práticas na administração pública pela auditoria operacional serve de alento aos que fiscalizam a área, no caso os auditores do TCE/PB, o que pode explicar o grau de importância alcançado pelo estímulo às boas práticas da administração pública.

Entre os benefícios potenciais menos importantes da auditoria operacional, na percepção dos pesquisados, estão os referentes à contribuição para accountability, ao fomento ao controle social, à redução dos custos, à qualificação da informação divulgada, à melhoria das relações entre auditoria e auditado e ao aumento de receitas, com pontuação entre 189 e 259.

O termo accountability compreende a ideia de obrigação de prestação de contas. Mas nem sempre essa prestação de contas ocorre de maneira efetiva. O cidadão até cobra, e tem aumentado essa cobrança, mas, por um lado, as contas são prestadas em uma linguagem com perfil mais técnico e por outro lado o cidadão não se municia de informações vitais para avaliar em profundidade os gestores e a gestão pública. A auditoria operacional tem o benefício de oportunizar mais elementos informativos ao cidadão. No entanto, os tribunais de contas não conseguiram, ainda, comunicar os resultados de suas análises de maneira mais prática, mais próxima do cidadão, ou, até mesmo, de despertar um maior interesse do cidadão, o que pode justificar a percepção dos auditores do TCE/PB de menos importante em relação ao potencial benefício da auditoria operacional de servir de contribuição para a accountability da administração pública.

Como o de menor importância foi percebido o benefício potencial de possibilitar a melhoria da supervisão exercida pelo Poder Legislativo, tendo obtido 276 pontos. O fato de que os tribunais de contas disputam a atenção dos integrantes do Poder Legislativo com muitas outras vozes da sociedade, possivelmente, pode explicar essa percepção dos pesquisados. 


\subsection{PERCEPÇÃO DOS AUDITORES DO TCE/PB QUANTO À POSSIBILIDADE DE MATERIALIZAÇÃO DOS BENEFÍCIOS POTENCIAIS DA AUDITORIA OPERACIONAL}

Na Tabela 1 é demonstrada, na visão dos auditores do TCE/PB, a possibilidade de materialização dos principais benefícios potenciais da auditoria operacional na administração pública.

Considerando-se os percentuais de "muito alta” e de "alta”, o benefício potencial da auditoria operacional de maior possibilidade de materialização na administração pública é o de melhoria do debate sobre as políticas governamentais, com 73\% das respostas. De acordo com a doutrina, a melhoria do debate pode ocorrer se os aspectos trabalhados pela auditoria operacional forem contemporâneos aos fatos, o que ajuda a justificar essa percepção.

Os benefícios potenciais seguintes com maiores possibilidades de materialização são os relacionados à solidificação da legitimidade dos tribunais de contas, à avaliação dos objetivos de programas e de organizações, à avaliação dos resultados com foco no cidadão, ao estímulo às boas práticas, à melhoria de desempenho, à qualificação da informação divulgada, à melhoria nas relações entre auditoria e auditado, à escolha de objetos do interesse da sociedade e à diminuição de desperdícios, com percentuais que variam de $50 \%$ a $68 \%$ das respostas.

Considerando-se os percentuais de “pequena” e de "remota”, os benefícios potenciais com menores possibilidades de materialização são os que têm relação com a melhoria da supervisão exercida pelo Poder Legislativo e com o aumento de receitas, na percepção dos pesquisados.

Com percentuais de respostas inferiores a 50\% tanto para maiores quanto para menores chances de materialização, os benefícios potenciais com possibilidades moderadas de materialização são os de fomento ao controle social, de redução de custos e de contribuição para a accountability. 
Tabela 1 - Possibilidade de materialização de benefícios potenciais da auditoria operacional

\begin{tabular}{|c|c|c|c|c|c|}
\hline \multirow{2}{*}{ Benefícios potenciais } & \multicolumn{5}{|c|}{ Possibilidades de materialização (\%) } \\
\hline & $\begin{array}{c}\text { Muito } \\
\text { alta }\end{array}$ & Alta & Moderada & Peque-na & Remota \\
\hline $\begin{array}{l}\text { Melhoria do desempenho da adminis- } \\
\text { tração pública. }\end{array}$ & 23 & 36 & 27 & 14 & 0 \\
\hline $\begin{array}{l}\text { Diminuição de desperdícios e de } \\
\text { práticas ineficientes, antieconômicas, } \\
\text { ineficazes e abusivas. }\end{array}$ & 9 & 41 & 27 & 9 & 14 \\
\hline $\begin{array}{l}\text { Estímulo às boas práticas da adminis- } \\
\text { tração pública. }\end{array}$ & 28 & 36 & 27 & 9 & 0 \\
\hline $\begin{array}{l}\text { Avaliação de resultados da adminis- } \\
\text { tração pública com foco no cidadão. }\end{array}$ & 37 & 27 & 27 & 9 & 0 \\
\hline $\begin{array}{l}\text { Avaliação dos objetivos de programas } \\
\text { e de organizações. }\end{array}$ & 27 & 41 & 14 & 14 & 4 \\
\hline $\begin{array}{l}\text { Melhoria do debate sobre as políticas } \\
\text { governamentais. }\end{array}$ & 23 & 50 & 23 & 0 & 4 \\
\hline $\begin{array}{l}\text { Solidificação da legitimidade do } \\
\text { sistema de controle externo exercido } \\
\text { pelos tribunais de contas. }\end{array}$ & 32 & 36 & 23 & 9 & 0 \\
\hline $\begin{array}{l}\text { Escolha de objetos de avaliação que } \\
\text { sirvam ao interesse público e à so- } \\
\text { ciedade. }\end{array}$ & 27 & 23 & 27 & 23 & 0 \\
\hline Contribuição para a accountability. & 14 & 32 & 23 & 31 & 0 \\
\hline Fomento ao controle social. & 9 & 18 & 68 & 0 & 5 \\
\hline Redução de custos. & 4 & 27 & 23 & 32 & 14 \\
\hline $\begin{array}{l}\text { Divulgação de informação mais } \\
\text { qualificada. }\end{array}$ & 14 & 41 & 41 & 4 & 0 \\
\hline $\begin{array}{l}\text { Melhoria das relações entre auditoria } \\
\text { e auditado. }\end{array}$ & 14 & 41 & 32 & 13 & 0 \\
\hline Aumento de receitas. & 0 & 4 & 32 & 32 & 32 \\
\hline $\begin{array}{l}\text { Melhoria da supervisão exercida pelo } \\
\text { Poder Legislativo. }\end{array}$ & 0 & 5 & 27 & 45 & 23 \\
\hline
\end{tabular}

Fonte: os autores. 


\subsection{CONFRONTO ENTRE A IMPORTÂNCIA E A POSSIBILIDADE DE MATERIALIZAÇÃO DOS BENEFÍCIOS POTENCIAIS DA AUDITORIA OPERACIONAL}

Na Tabela 2 apresenta-se um confronto entre a importância e a possibilidade de materialização dos benefícios potenciais da auditoria operacional, considerando-se as respostas dos auditores do TCE/PB.

Tabela 2 - Importância versus possibilidade de materialização de benefícios potenciais da auditoria operacional

\begin{tabular}{|c|c|c|c|c|}
\hline \multirow{2}{*}{ Benefícios potenciais } & \multicolumn{3}{|c|}{ Possibilidades de materialização (\%) } & \multirow{2}{*}{$\begin{array}{l}\text { Ordem de impor- } \\
\text { tância }\end{array}$} \\
\hline & Maiores & Moderadas & Menores & \\
\hline $\begin{array}{l}\text { Melhoria do desempenho da } \\
\text { administração pública. } \\
\text { Diminuição de desperdícios e de }\end{array}$ & 59 & 27 & 14 & $1^{\circ}$ \\
\hline $\begin{array}{l}\text { práticas ineficientes, antieconô- } \\
\text { micas, ineficazes e abusivas. }\end{array}$ & 50 & 27 & 23 & $2^{\circ}$ \\
\hline $\begin{array}{l}\text { Estímulo às boas práticas da } \\
\text { administração pública. }\end{array}$ & 64 & 27 & 9 & $3^{\circ}$ \\
\hline $\begin{array}{l}\text { Avaliação de resultados da } \\
\text { administração pública com foco } \\
\text { no cidadão. }\end{array}$ & 64 & 27 & 9 & $4^{\circ}$ \\
\hline $\begin{array}{l}\text { Avaliação dos objetivos de pro- } \\
\text { gramas e de organizações. }\end{array}$ & 68 & 14 & 18 & $5^{\circ}$ \\
\hline $\begin{array}{l}\text { Melhoria do debate sobre as } \\
\text { políticas governamentais. }\end{array}$ & 73 & 23 & 4 & $6^{\circ}$ \\
\hline $\begin{array}{l}\text { Solidificação da legitimidade do } \\
\text { sistema de controle externo exer- } \\
\text { cido pelos tribunais de contass } \\
\text { Escofha de objetos de avaliaçẫo }\end{array}$ & 68 & 23 & 9 & $7^{\circ}$ \\
\hline $\begin{array}{l}\text { que sirvam ao interesse público e } \\
\text { à sociedade. }\end{array}$ & 50 & 27 & 23 & $8^{\circ}$ \\
\hline $\begin{array}{l}\text { Contribuição para a accounta- } \\
\text { bility. }\end{array}$ & 46 & 23 & 31 & $9^{\circ}$ \\
\hline Fomento ao controle social. & 27 & 68 & 5 & $10^{\circ}$ \\
\hline Redução de custos. & 31 & 23 & 46 & $11^{\circ}$ \\
\hline $\begin{array}{l}\text { Divulgação de informação mais } \\
\text { qualificada. }\end{array}$ & 55 & 41 & 4 & $12^{\circ}$ \\
\hline $\begin{array}{l}\text { Melhoria das relações entre } \\
\text { auditoria e auditado. }\end{array}$ & 55 & 32 & 13 & $13^{\circ}$ \\
\hline Aumento de receitas. & 4 & 32 & 64 & $14^{\circ}$ \\
\hline $\begin{array}{l}\text { Melhoria da supervisão exercida } \\
\text { pelo Poder Legislativo. }\end{array}$ & 5 & 27 & 68 & $15^{\circ}$ \\
\hline
\end{tabular}


Aponte-se que o percentual das maiores possibilidades é resultante do somatório dos percentuais das opções "muito alta” e “alta”. Já o percentual das menores possibilidades decorre do somatório dos percentuais de “pequena” e "remota”.

Verifica-se que os oito benefícios potenciais mais importantes têm maiores possibilidades de materialização. Chama a atenção o fato de os dois benefícios potenciais menos importantes, que são os de aumento de receitas e de melhoria da supervisão exercida pelo Poder Legislativo, serem os que têm menores possibilidades de materialização, na opinião dos pesquisados.

\section{CONCLUSÃO}

Neste estudo buscou-se analisar a percepção dos auditores do TCE/PB sobre os benefícios potenciais da auditoria operacional e a possibilidade da materialização deles na administração pública. Para alcançar esse objetivo, realizou-se uma revisão da literatura sobre a evolução da administração pública brasileira, os aspectos gerais da auditoria operacional e o apontamento pela doutrina dos principais benefícios potenciais. Na sequência aplicou-se um questionário a auditores do TCE/PB, visando obter a percepção deles.

No ver dos auditores do TCE/PB, os benefícios da auditoria operacional mais importantes para a administração pública são os que têm relação com o desempenho, com a diminuição de desperdícios, com as boas práticas, com o foco no cidadão, com os objetivos de programas e de organizações e com o debate sobre as políticas governamentais. Essa visão traz um alento diante das atuais necessidades da administração pública, principalmente a de melhorar seu desempenho.

Quanto à materialização dos benefícios potenciais das auditorias operacionais em prol da administração pública, a percepção dos auditores do TCE/PB é que, dos 15 benefícios potenciais apontados pelos estudiosos, 10 têm grandes possibilidades de se tornarem realidade. Têm-se tais números como relevantes para a administração pública, com repercussão na melhoria do debate sobre as políticas governamentais, na avaliação dos objetivos de programas e de organizações, na legitimação dos tribunais de contas, na avaliação de resultados com foco no cidadão, no estímulo a boas práticas, na melhoria de desempenho, na divulgação de informações mais qualificadas, na melhoria das relações entre auditoria e auditado, na diminuição de desperdícios e práticas inadequadas e na escolha de objetos do interesse da sociedade.

Os dados apurados em decorrência da percepção dos auditores do TCE/PB conduzem para a conclusão de que os benefícios da auditoria operacional se mostram 
com potencial de melhoria da administração pública. E, considerando as exigências de que o Governo seja cada vez mais transparente e eficiente, a auditoria operacional se apresenta como um importante instrumento de avaliação, tornando-se uma tendência irreversível na administração pública. Registrem-se, como limitações do estudo, o fato de a descrição da auditoria operacional no contexto do TCE/PB ter sido baseada em informações disponíveis apenas no portal eletrônico do Tribunal e o fato de a análise dos benefícios da auditoria operacional na administração pública restringir-se à percepção de auditores do TCE/PB.

Considerando-se as cooperações técnicas entre os tribunais de contas brasileiros, principalmente as voltadas para a auditoria operacional, tanto em termos de aprimoramento dos procedimentos quanto de proposição de possíveis áreas ou aspectos a serem analisados, os resultados apurados neste estudo podem ser generalizados para os demais tribunais de contas do Brasil.

Aproveita-se para sugerir outras pesquisas para, por exemplo, investigar a percepção de gestores públicos sobre os benefícios potenciais da auditoria operacional e verificar resultados decorrentes das recomendações de auditorias operacionais.

\section{REFERÊNCIAS}

ALMEIDA, C. W. L. de. Auditoria operacional: conceito, proposta e crítica. Revista do TCU, Brasília, DF, n. 123, p. 42-59, jan./abr. 2012. Disponível em: <http://portal2.tcu.gov.br/portal/pls/portal/docs/2494434.PDF>. Acesso em: 18 dez. 2014.

ALMEIDA, C. W. L. de. Resultados das auditorias operacionais do TCU sobre a defesa aeroespacial. Revista do TCU, Brasília, DF, n. 129, p. 50-65, jan./abr. 2014. Disponível em: <http://portal2.tcu.gov.br/portal/pls/portal/docs/2657720.PDF>. Acesso em: 28 nov. 2014.

ARAÚJO, I. da P. S. Introdução à auditoria operacional. 4. ed. Rio de Janeiro: Ed. FGV, 2008.

AUDITOR destaca dez princípios da auditoria operacional. Tribunal de Contas da União, Brasília, DF, 28 set. 2010. Disponível em: <http://portal2.tcu.gov.br/portal/ page/portal/TCU/imprensa/noticias/detalhes_noticias?noticia=2734310>. Acesso em: 15 jan. 2015.

BACK, S. M. C. Auditoria operacional: sua aplicação, implementação e realização pelo Tribunal de Contas do Rio Grande do Sul. Revista do TCE/RS, Porto Alegre, n. 9, p. 120-124, jun. 1991. 
BRASIL. Câmara da Reforma do Estado. Plano Diretor da Reforma do Aparelho do Estado - PDRAE. Brasília, DF: MARE, 1995. Disponível em: <http://www. bresserpereira.org.br/documents/mare/planodiretor/planodiretor.pdf $>$. Acesso em: 05 nov. 2014.

BRASIL. Lei Complementar n. 101, de 04 de maio de 2000. Estabelece normas de finanças públicas voltadas para a responsabilidade na gestão fiscal e dá outras providências. Diário Oficial da União, Brasília, DF, 05 de maio de 2000. Disponível em: <http://www.planalto.gov.br/ccivil_03/leis/lcp/lcp101.htm>. Acesso em: 15 nov. 2014.

BRASIL. Tribunal de Contas da União. Manual de auditoria operacional. 3. ed. Brasília, DF: TCU, 2010. Disponível em: <http://portal2.tcu.gov.br/portal/pls/portal/ docs/2058980.PDF>. Acesso em: 20 nov. 2014.

BRITTO, É. A. de. Governança e accountability no setor público: auditoria operacional como instrumento de controle das ações públicas a cargo do TCEMG. Revista TCEMG, Belo Horizonte, p. 53-70, jan./fev./mar. 2014. Disponível em: <http:// revista.tce.mg.gov.br/Content/Upload/Materia/2421.pdf>. Acesso em: 28 mar. 2015.

COOPER, D. R.; SHINDLER, P. S. Métodos de pesquisa em administração. 7. ed. Porto Alegre: Bookman, 2003.

DIAS NETO, L. G. Auditoria operacional: os tribunais de contas sob nova perspectiva. Revista Controle do TCE/CE, Fortaleza, p. 85-89, dez. 2005. Disponível em: <http://www.tce.ce.gov.br/component/jdownloads/finish/227-revista-controle-dezembro-2005/1073-opiniao-1-auditoria-operacional-os-tribunais-de-contas-sob-nova-perspectiva?Itemid=592> . Acesso em: 14 mar. 2015.

DINIZ, G. M.; MUNIZ JÚNIOR, J. A contribuição da auditoria operacional executada nos Tribunais de Contas para as boas práticas de governança política: uma proposta de pesquisa à luz da filosofia. Fortaleza: MPCE, 2013. Disponível em: <http://www.mpce.mp.br/esmp/publicacoes/Edital-02-2013/Artigos/02-Gleison. Mendonca.Diniz.pdf>. Acesso em: 13 nov. 2014.

FEIL, L. Auditoria operacional na gestão pública: estudo de caso no Tribunal de Contas do Estado de Santa Catarina - TCE/SC. 2007. 80 p. Trabalho de Conclusão de Curso (Graduação de Bacharel em Ciências Contábeis)-Universidade Federal de Santa Catarina, Florianópolis, 2007. Disponível em: <http://tcc.bu.ufsc.br/Contabeis293879>. Acesso em: 04 abr. 2015. 
GIL, A. C. Como elaborar projetos de pesquisa. 4. ed. São Paulo: Atlas, 2002.

LEAL, M. A. P. A auditoria operacional e sua contribuição para a melhoria da gestão pública: um estudo de caso da auditoria operacional da Agência Estadual de Meio Ambiente e Recursos Hídricos em Pernambuco. 2006. 137 p. Dissertação (Mestrado em Administração)-Universidade Federal da Bahia, Salvador, 2006. Disponível em: <http://www.adm.ufba.br/pt-br/publicacao/auditoria-sua-contribuicao-para-melhoria-gestao-publica-estudo-caso-auditoria-operacional>. Acesso em: 03 nov. 2014.

MARTINS, G. de A.; LINTZ, A. Guia para elaboração de monografias e trabalhos de conclusão de curso. São Paulo: Atlas, 2000.

MELATI, C. Socialização organizacional na Secretaria da Administração e dos Recursos Humanos do Rio Grande do Sul. 2013. 56 p. Monografia (Especialização em Administração Pública Contemporânea)-Universidade Federal do Rio Grande do Sul, Porto Alegre, 2013. Disponível em: <http://www.lume.ufrgs.br/handle/10183/101893>. Acesso em: 29 out. 2015.

MORAES, A. C. F. de. Legalidade, eficiência e controle da administração pública. Belo Horizonte: Fórum, 2007.

NAVES, L. E. P. Auditorias operacionais a cargo dos tribunais de contas brasileiros e accountability vertical e horizontal: análise do processo de institucionalização depois de 1988. 2012. Dissertação (Mestrado em Administração Pública)-Fundação João Pinheiro, Belo Horizonte, 2012. Disponível em: <http://www. radarciencia.org//Record/oai-fjp-mg-gov-br-144>. Acesso em: 03 nov. 2014.

OLIVEIRA, V. G.; SIQUEIRA, L. G. A auditoria operacional como forma de controle social: caso do transporte escolar no município de Bandeirantes - PR. 2012. 96 p. Trabalho de Conclusão de Curso (Graduado em Administração)-Universidade Estadual do Norte do Paraná -Procópio, 2012. Disponível em: <http:// uenp.edu.br/tcc/ccp/adm/2012/03-A\%20auditoria\%20operacional\%20social\%20 como\%20forma\%20de\%20controle\%20social.pdf>. Acesso em: 28 nov. 2014.

OLIVIERI, C. et al. Do controle interno ao controle social: a múltipla atuação da CGU na democracia brasileira. Cadernos Gestão Pública e Cidadania, São Paulo, v. 17, n. 60, p. 54-67, jan./jun. 2012. Disponível em: <http://bibliotecadigital.fgv.br/ ojs/index.php/cgpc/article/download/3980/2851>. Acesso em: 21 set. 2016. 
PAULA, E. P. de. O tribunal de contas e a auditoria de programas na melhoria do gasto público dos municípios fluminenses e do governo do Estado. Conteúdo Jurídico, Brasília, DF, abr. 2012. Disponível em: <http://www.conteudojuridico. com.br/artigo,o-tribunal-de-contas-e-a-auditoria-de-programas-na-melhoria-do-gasto-publico-dos-municipios-fluminenses-e-do-g,36366.html>. Acesso em: 31 jan. 2015.

RIBEIRO FILHO, J. F. et al. Recomendações em auditoria operacional: uma prospecção de fragilidades, com base na inteligência competitiva. Rev. Adm. UFSM, Santa Maria, v. 3, n. 2, p. 191-204, maio/ago. 2010. Disponível em: <http:// cascavel.ufsm.br/revistas/ojs-.2.2/index.php/reaufsm/article/view/2333/1406>. Acesso em: 28 dez. 2014.

SILVA, E. de S. Auditoria operacional: um instrumento de controle social. Revista Gestão Pública e Controle do TCE/BA, Salvador, v. 1, n. 2, p. 177-205, ago. 2006.

SILVA, M. T. R. da. Experiências de auditoria de desempenho: uma contribuição do seminário internacional de auditoria operacional. Revista do TCE/BA, Salvador, p. 103-114, 2012/2013.

SOUZA, A. M. O. Auditorias operacionais: controle substancial da gestão pública pelos tribunais de contas. 2007. 229 p. Dissertação (Mestrado em Direito)-Universidade Federal da Bahia, Salvador, 2007. Disponível em: <https://repositorio.ufba.br/ ri/bitstream/ri/10779/1/Adrianne.pdf>. Acesso em: 20 dez. 2014.

SPECK, B. W. Estratégia para melhorar o relacionamento entre Tribunais de Contas Estaduais com a sociedade civil: uma estratégia para aumentar a eficácia da auditoria governamental nos estados brasileiros. Revista do TCE/BA, Salvador, p. 61-69, 2012, 2013a.

SPECK, B. W. Estratégia para melhorar o relacionamento entre Tribunais de Contas Estaduais com o Poder Legislativo: uma estratégia para aumentar a eficácia da auditoria governamental nos estados brasileiros. Revista do TCE/BA, Salvador, p. 70-81, 2012, 2013b.

TEIXEIRA, M. A. C. et al. Controles democráticos sobre a administração pública no Brasil: Legislativo, Tribunais de Contas, Judiciário e Ministério Público. Burocracia e Política no Brasil Contemporâneo. Rio de Janeiro: Ed. FGV, 2010. Disponível em: <https://gbapufabc2014.files.wordpress.com/2014/06/arantes_2011_ controles-democrc3a1ticos-sobre-a-administracao-pc3bablica-no-brasil.pdf $>$. Acesso em: 21 set. 2016. 
TRIBUNAL DE CONTAS DO ESTADO DA PARAÍBA. Portal da Cidadania SAGRES. João Pessoa: TCE/PB, 2015. Disponível em: <https://sagres.tce.pb.gov. br/estado_pessoal04.php?poder=5\&ano=2015\&competencia=062015\&tipo=EFETIVO\%20ATIVO\&descricao=Junho>. Acesso em: 23 out. 2015.

\section{Como citar este artigo:}

\section{ABNT}

MELO, Gentil Jose Pereira de; PAIVA, Simone Bastos. Benefícios potenciais da auditoria operacional para a administração pública: a percepção dos auditores do TCE/PB. RACE, Revista de Administração, Contabilidade e Economia, Joaçaba: Ed. Unoesc, v. 16, n. 1, p. 353-380, jan./abr. 2017. Disponível em: <http://editora. unoesc.edu.br/index.php/race>. Acesso em: dia/mês/ano.

\section{APA}

Melo, G. J. P. de, \& Paiva, S. B. (2017). Benefícios potenciais da auditoria operacional para a administração pública: a percepção dos auditores do TCE/PB. RACE, Revista de Administração, Contabilidade e Economia, 16(1), 353-380. Recuperado em dia/mês/ano, de http://editora.unoesc.edu.br/index.php/race 